International Journal of Biological Research, $2(2)(2014) 48-50$
International Journal of Biological Research
Sournal home page: www.sciencepubco.com/index.php/IJBR
doi: $10.14419 /$ ijbr.v2i2.2540
Research Paper

\title{
Intestinal coccidiosis infection in domestic rabbits
}

\author{
S. Sivajothi ${ }^{1 *}$, B. Sudhakara Reddy ${ }^{2}$, V. C. Rayulu ${ }^{1}$ \\ ${ }^{1}$ Department of Veterinary Parasitology, College of Veterinary Science, Sri Venkateswara Veterinary University, \\ Proddatur - 516360, Andhra Pradesh, India \\ ${ }^{2}$ Assistant Professor (Veterinary Medicine), Teaching Veterinary Clinical Complex, C.V.Sc., S.V.V.U., Proddatur \\ *Corresponding author E-mail: sivajothi579@gmail.com
}

\begin{abstract}
The present study reports about the intestinal coccidiosis in a commercial rabbit farm. Seven New Zealand white rabbits were died in a commercial rabbit farm in Tirupati during the month of August. All the rabbits had signs of anorexia, diarrhea, dullness and weakness. Rabbits were necropsied and collected the intestinal contents for laboratory examination. Up on post mortem examination, hyperemic and oedematous intestinal mucosa was noticed. Oocysts of Eimeria spp. were detected in the faeces of all the rabbits. The collected oocysts were transferred into $2.5 \%$ aqueous potassium dichromate solution for sporulation. Faecal samples were examined by modified McMaster technique to determine oocyst counts which had ranged from 13,200 to 16,400.
\end{abstract}

Keywords: Intestinal Coccidiosis, OPG, Rabbits, Sporulation.

\section{Introduction}

Coccidiosis is caused by intracellular protozoon parasites of the genus Eimeria and causes significant mortality in domestic rabbits. Coccidiosis is one of the most frequent and prevalent parasitic diseases, accompanied by weight loss, mild intermittent to severe diarrhea with faeces containing mucus or blood and results in dehydration, decreased rabbit breeding (Jithendran and Bhat, 1996). The disease is seen most often in rearing establishments where sanitation is poor. So far, 15 species of Eimeria in rabbit have been identified (El-Shahawi et al., 2012). Of them, 14 are known to infect the intestine while one is located in the biliary ducts of the liver. Two types of coccidiosis, intestinal and hepatic are described in rabbits. The intestinal coccidial species causes weight reduction, diarrhoea and mortality due to villi atrophy will lead to malabsorption of nutrients, electrolyte disbalance, anaemia, hypoproteinemia and dehydration (Karaer 2001). The rabbit intestinal coccidia parasitize distinct parts of the intestine and in different depths of the mucosa (Pakandl, 2009).The causal agents of rabbit coccidiosis develop direct life cycle multiplying very fast and leading to massive infection, especially in young rabbits (Gres et al., 2003; Pakandl, 2009). Adults which are usually symptomless carriers of coccidial infection serve as a potential source of severe infection with clinical signs resulting in the death of young ones. The present report is on intestinal coccidiosis in young rabbits in an organized farm.

\section{Materials and methods}

Present study was conducted on the seven rabbits (New Zealand white rabbits) belongs to the 2-3 months of age which were died by exhibiting the signs of diarrhea and weakness from a comercial rabbit farm in Tirupati in the month of August. All the rabbits were regularly feed with carrots and green grass. Post mortem examinations of the rabbits were done and primary gross pathologic changes were noticed in the intestines. Intestines were removed along with their contents and they were subjected to examination for Eimeria infection. Faecal samples were examined for the presence of parasitic oocysts by direct microscopic examination, sedimentation technique. Positive samples were subjected to floatation technique using saturated salt solution (Long et al., 1976) to collect and concentrate the oocysts. The collected oocysts were transferred into $2.5 \%$ aqueous potassium dichromate solution (w/v) and incubated at $25-28^{\circ} \mathrm{C}$ to allow the oocysts to sporulate and examined periodically to determine the sporulation time. A modified McMaster technique was used to determine oocysts counts per gram of faeces (OPG) in samples.

\section{Results}

All the rabbits had low body condition score, emaciation with reduced fat stores and muscle wasting. The hair coat was rough and faecal material was adherent to the hair on the perineum. Primary gross pathologic changes were observed in small intestines which found to be distended and filled with gray-greeen semisolid ingesta. The intestinal mucosa was severely hyperemic and oedematous. Macroscopic lesions were observed neither in the liver nor in the other organs. In the present study sporulation time of 72 hours could be observed at room temperature. Initially, the oocysts were non-sporulated. In this study, direct smears of the faecal sample examination revealed the presence of unsporulated oocysts (Figure-1) and up on sporulation, sporulated oocysts were noticed (Figure-2). Oocysts counts were ranged from 13,200 to 16,400. 


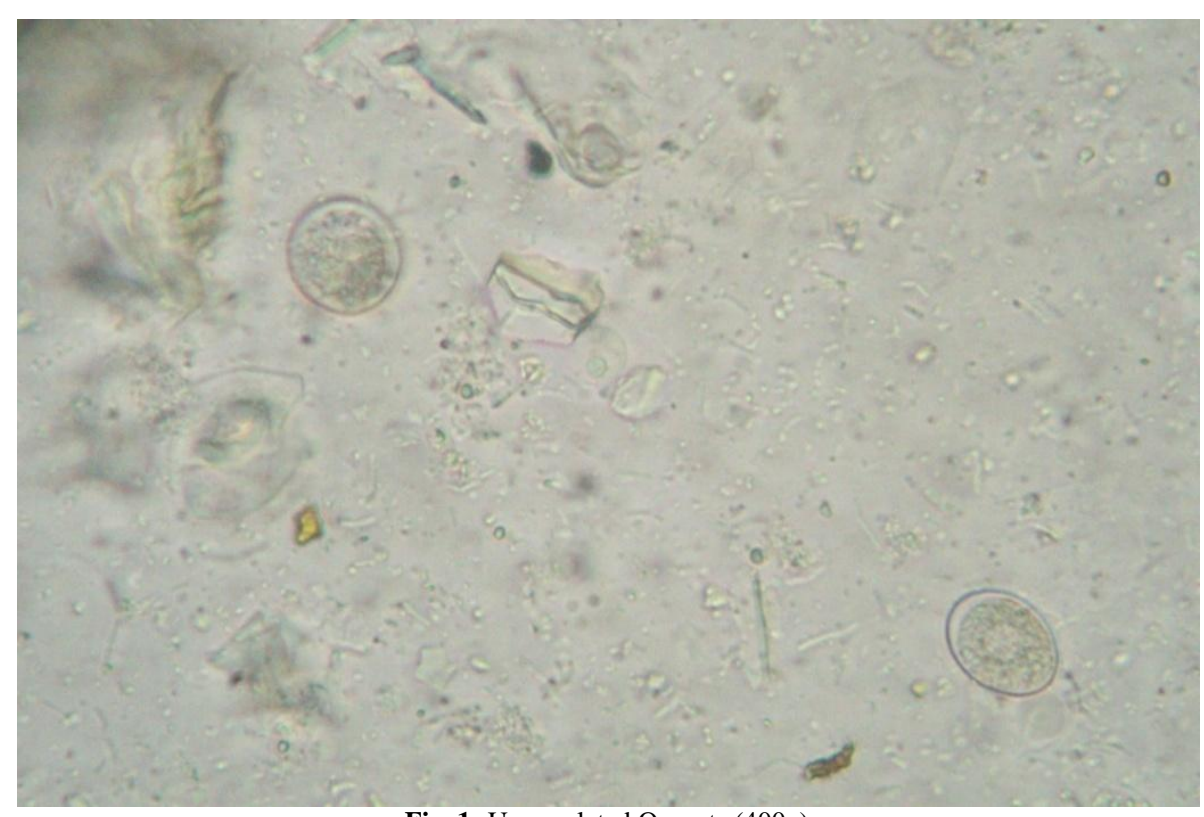

Fig. 1: Unpopulated Oocysts (400x)

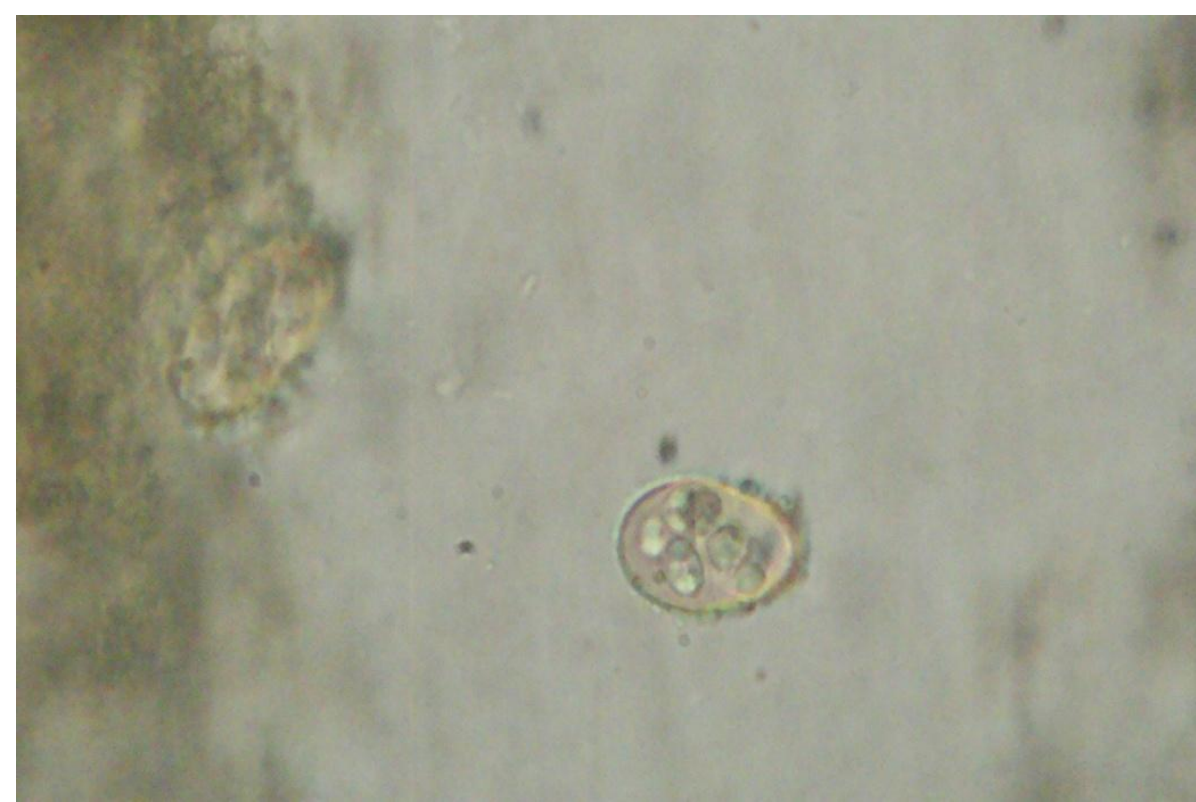

Fig. 2: Sporulated Oocysts (400x)

\section{Discussion}

Intestinal coccidia cause severe disease in rabbits and the severity depends up on the infective dose, parasite species, immune status and age of animals. Adult rabbits are usually symptomless carriers of coccidian infections (Coudert et al., 2000). The clinical signs of the disease depend on its location. Intestinal coccidiosis results in weight loss, soft to watery feces, blood in feces, dehydration, increased thirst, and sometimes death. Symptoms can range from no visible symptoms to loss of appetite, failure to gain weight, depression, swollen belly, abdominal pain, pale mucus membranes and diarrhea.

Findings from this study suggest that the mothers may play an important role in Eimeria transmission to the litters. The high level of susceptibility of infection in young rabbits may be due to their immune, feeding and reproductive status (Ebtesam 2008). The findings are in consonance with the previous results of Hobbs et al. (1999) and Erdogmus and Eroksuz (2006). E. flavescens and $E$. intestinalis are the most pathogenic species involved in intestinal coccidiosis of rabbits. In necropsy, inflammation and oedema can be seen in the infected rabbits. It is sometimes accompanied by bleedings and mucosal ulcerations (Coudert et al. 1995).

The sporulation time recorded in the present study was 72 hours. Variations in the sporulation time may be due to crowdedness of oocysts or depends on contamination. This may also support the opinion that different sporulation times may be related to different experimental factors or laboratory techniques or to the lack of adequate oxygen (Bashtar et al., 2010). Coccidiosis is considered to be a major problem in rabbits as mortality rate may go high particularly during and after rainy season (Singla et al., 2000). Present study report was also reported in the month of August, when the rainy season will start. Subclinical infections are more common with intestinal coccidiosis in rabbits. In this study also we find only emaciation associated with diarrhoea. Prevention is the best method in the control of rabbit coccidiosis. Sanitation and husbandry are the most important aspects in controlling the infection. 


\section{Conclusion}

Present communication reports the intestinal coccidiosis in young rabbits in a commercial farm during the rainy season. In this study diagnosis of the coccidiosis was done based on the clinical findings (progressive emaciation and diarrhea) along with identification of the organisms in the intestinal contents.

\section{Acknowledgements}

The authors acknowledge the authorities of Sri Venkateswara Veterinary University, Tirupati for providing facilities to carry out this research. Corresponding author was also thankful to the Reddamma, Veterinary Assistant who assisted in the sample collection.

\section{References}

[1] Bashtar AR, AL-Rasheid KA, Mobarak M, AL-Ghamdy AA (2003). Coccidiosis in rabbits from Saudi Arabia. 1. Exogenous stages of different Eimeria spp. J. Egypt. Ger. Soc. Zool., 42: 1-10.

[2] Coudert P, Licois D, Provot F, Drouet -Viard F (1995). Eimeria species and strains of rabbits. In: Eckert J, Braun R, Shirley MW, Coudert P, Editors: Guidelines on techniques in coccidiosis research. COST 89/820: Biotechnology. European Commission, Luxembourg, 52-73.

[3] Coudert P, Licois D, Zonnekeyn V (2000). Epizootic rabbit entercolitis and coccidiosis: a criminal conspiracy. In Proc.: 7th World Rabbit Congress, 7-4 July, 2000, Valence, Spain, 215-218.

[4] Ebtesam MM (2008). Hepatic coccidiosis of the domestic Rabbit Oryctolagus cuniculus domesticus L. In Saudi Arabia. World J Zool, 3, 3-35

[5] EL-Shahawi GA, EL-Fayomi HM, Abdelhaleem HM (2012). Coccidiosis of domestic rabbit (Oryctolagus cuniculus) in Egypt: light microscopic study. Parasitol. Res., 110: 251-258.

[6] Erdogmus ZS, Eroksuz Y (2006). Hepatic coccidiosis in Angora Rabbits. J Anim Vet Adv, 5, 462- 463.

[7] Gres V, Voza T, Chabaud A, Landau I (2003). Coccidiosis of the wild rabbit (Oryctolagus cuniculus) in France. Parasite, 10:51- 57.

[8] Hobbs RP, Twigg LE, Elliot AD, Wheeler AG (1999). Factors influencing the faecal egg and oocyst count of parasites of wild European rabbits Oryctolagus cuniculus in southern Western Australia. J parasitol, 85, 796-802.

[9] Jithendran KP, Bhat TK, Banerjee DP, Ghosh JD, Gupta SK (1996). Coccidiosis in Angora rabbits-a field study in Himachal Pradesh. Parasitic diseases-new horizons. Proceedings of the Eighth National Congress of Veterinary Parasitology and National Symposium on Molecular Parasitology, 9-11 October, 41-49.

[10]Karaer Z (2001). Evcil Tavşanlarda ( Oryctolagus cuniculus) Coccidiosis. In: Dinçer Ş., Ed. Coccidiosis. Türkiye Parazitoloji Derneği Yayınları, No.17. Meta Basım, İzmir, 269 -278.

[11]Pakandl M (2009). Coccidia of rabbit: a review. Folia Parasitol., 56 $153-166$. 